\title{
ARTERIO-SCLEROSIS IN CHILDREN
}

\author{
BY GEOFFREY EVANS \\ (From the Medical Unit, St. Bartholomew's Hospital)
}

\section{With Plates 3-5}

THE study of arterio-sclerosis in the adult led me to the conclusion that identical pathogenic factors might be responsible for different forms of arterial disease according to variations in the resilience of the tissues affected (1); that the difference between diffuse hyperplastic sclerosis and senile arterio-sclerosis, for instance, might be a question of varying physiological age response rather than a difference in the pathogenic agents involved. In other words, the younger the patient the more active was the type of tissue response to insult likely to be, and I expected to find the more active phases of arterio-sclerosis in children. This has been found to be the case in specimens to be described later which show endothelial cell proliferation in renal arterioles. Again, in elucidating the aetiology of arterio-sclerosis children provide a simpler material for study than do adults, because, by reason of their age, many of the aetiological factors that may be, or may have been, active in older subjects are a priori excluded. The difficulty, however, that occurs is the difficulty of obtaining suitable material, since the affection is not common in a well-developed form in children.

The four cases that form the subject of this communication are fairly complete in their clinical, chemico-patbological, and anatomico-pathological records. I had the opportunity of making the post-mortem examinations myself, and I am much indebted to Dr. H. Morley Fletcher, Dr. J. H. Drysdale, and Mr. Foster Moore for permission to see the patients during life and especially to publish the clinical records of their cases. Three of the cases have not been previously described ; Case I was shown by Dr. Morley Fletcher at a meeting of the Children's Section of the Royal Society of Medicine (2). The correlation of clinical and chemico-pathological (renal efficiency tests) observations with the post-mortem findings is of great interest, and it is on this account that the clinical details of Case I are repeated in this report. The first three cases belong to the type of chronic nephritis in childhood commonly named renal infantilism. The fourth case is different in some respects both clinically and pathologically, but in the similarity of the renal and cardio-vascular affection it is sufficient for the present purpose to place it in the same group with the other three. Similar cases 
to those described here have been reported by several authors (3), (4), (5), (6), (7), and (8), who give references to other cases in the literature. The outstanding feature of the present series of cases was the marked degree of cardiac hypertrophy and abnormally raised blood-pressure.

\section{Clinical and Pathological Records.}

Case I. Female, aged 14, admitted to hospital under the care of Dr. Morley Fletcher, three months before death, complaining of weakness and headache.

H.P.C. Onset insidious and perhaps congenital; she was 'small and delicate all her life', 'very weak since birth', liable to frontal headaches and nocturnal enuresis for years past. For a few weeks before admission there was complaint of pain and deafness in the right ear; no aural discharge. No history of gastro-intestinal disorder.

$P . H$. Scarlet fever two years previously, an illness which did not seem to have a permanent influence on her already weak state of health.

$F . H$. Nothing indicative of syphilis.

$P . C$. In physique a 'renal dwarf'. A very small body, pallid and wasted; no sign of puberty. Weight 2 st. $7 \mathrm{lb}$. No enlargement of the liver or spleen; no sign of syphilis; blood W. R. negative. No oedema. There was marked cardiae hypertrophy; the radial artery was small and wiry ; marked thickening of the carotid arteries and very marked arterial pulsation in them. The bloodpressure varied between $250 \mathrm{~mm}$. Hg systolic, $170 \mathrm{~mm}$. $\mathrm{Hg}$ diastolic, and $175 \mathrm{~mm}$. Hg systolic, $135 \mathrm{~mm}$. Hg diastolic. Mr. Foster Moore's note on the optic disks was as follows: 'Disks obscured by oedema, themselves are somewhat pale. Arteries and veins are diminished in size. The veins are cut into where the arteries cross them. Haemorrhages are scarce and small ; in each eye a particularly well-marked star figure. In a few places well-marked sclerosis of the choroidal vessels is visible. From the pallor and absence of marked swelling of the disk, the small retinal vessels, the absence of haemorrhages, and the pigmentary changes I should judge that retinal changes have been present for some time.'

Urine. Pale, slightly turbid, no deposit, acid; sp. g. 1010, 0.3 per cent. protein, of which a considerable proportion was globulin. The centrifugalized deposit contained numerous R. B.C., less numerous W. B. C., a few granular casts, no crystals. Blood urea $90 \mathrm{mg}$. per cent., later $168 \mathrm{mg}$. per cent. MacLean's concentration test: Urine before the test contained 1 per cent. urea; in the first hour after giving $5 \mathrm{grm}$. of urea the specimen contained 0.9 per cent.; the specimen passed at the end of the second hour also contained 0.9 per cent. Urinary diastase 10 units. Blood-sugar 0.1 grm. per cent. Temperature normal during the three months in hospital; pulse-rate generally about 110 . In the last few days there was ingravescent coma, and death occurred on June 3,1920 , in a convulsion. The outstanding clinical features were the retarded development, poor physique, and wasting, good mentality (7th standard at school), the marked renal insufficiency, and the great degree of the cardio-vascular affection.

Post-mortem, 4.6.20. Uraemia. Chronic nephritis; atrophy of the left kidney; right, pale and granular. Hypertrophy of left ventricle. Arteriosclerosis affecting the aorta, coronary arteries, and carotid. Heart, $7 \frac{3}{4}$ oz.; marked hypertrophy left ventricle, muscle pale, good firm texture. Vessels: marked sclerosis of the arch and descending aorta, irregular oval and circular plaques of intimal thickening, some pale and semi-translucent, others yellow (fatty); in descending aorta two areas of fibrosis. No ulceration. Common iliacs normal, except for medial hypertrophy, which was marked in all arteries, including the aorta. Mesenteric vessels normal. Right carotid showed marked longitudinal streaks of fatty intimal degeneration. Left carotid not opened. Early nodular 
sclerosis at the beginning of both coronary arteries. Marked nodular sclerosis in middle cerebral arteries and in their branches : circle of Willis similarly affected to a less extent. Right radial artery appeared normal. Pituitary, thyroid, and thymus glands normal. Suprarenals much hypertrophied. Kidneys: right $1 \frac{3}{4}$ oz., adherent to perirenal tissues, which were not themselves thickened or matted. Small vessels in abnormal number run in from perirenal tissues through capsule to cortex of kidney. Organ shrunken, not deformed, surface pale and mottled, intensely granular, the granulations uneven and coarse. Cut with resistance. Pelvis onlarged and inflamed; no peri-pelvic fat. Cortex atrophied to a thin line and normal kidney structure lost; large areas of pale fibrosis give mottled appearance to cut surface in which pyramids appeared dark by contrast. Capsule thickened and stripped with difficulty, tearing the renal substance. Left, $\frac{1}{4} \mathrm{oz}$. Similar, but the changes were of extreme degree. In both the renal vessels stood out on section like little quills. C.S. F. urea post mortem $660 \mathrm{mg}$. per cent. (Dr. Canti). Ureters large, somewhat dilated. Bladder-wall somewhat hypertrophied. Urethra and ureteric openings normal. Uterus infantile.

Histology. ${ }^{I}$ Advanced chronic nephritis. The most prominent changes were in the interstitial tissues. There was great increase in the fibrous tissue, diffuse small-cell infiltration and extreme obliterative endarteritis affecting the vasa recta to such an extent as almost to obliterate the lumen of many vessels; the parent arteries of these vessels were similarly affected to a less extent. There was no fatty degeneration in the majority of these arteries. The terminal arterioles, the vasa afferentia, were much reduced in number; typical examples of type seen in diffuse hyperplastic sclerosis in adults were present. There was extreme atrophy of the parenchyma. The glomeruli were reduced in number, those that remained were mostly reduced to fibrous nodules; some that were less completely destroyed showed endoglomerulitis with proliferation of the epithelial cells of Bowman's capsule and adhesion of the parietal and visceral layers. The tubules in some areas were conspicuously absent. Those that had escaped destruction were atrophied and dilated, while there were also sparse areas of tubules that had undergone a compensatory hypertrophy ; some of the hypertrophied tubules had undergone fatty degeneration.

The prominence of the fibrosis and small-cell infiltration in the histological picture has led to the opinion that the interstitial tissues bear the brunt of the insult in this affection; hence the condition is generally called 'chronic interstitial nephritis'. The parenchyma, however, is equally or more soverely damaged, and as a result is largely destroyed. Since all the tissues of the kidney are affected the lesion is better termed 'chronic nephritis'. The state of the arteries in other organs is given in tabular form on p. 39 for comparison with the other cases.

Case II. Male, aged 14, admitted to hospital under the care of Dr. Drysdale three months before death complaining of defective vision.

H.P.C. Onset insidious. The condition was first discovered seven years before death, when the patient had an epileptiform convulsion in hospital on the day following an operation. The child had been admitted on account of genu valgum and Macewen's osteotomy had been performed. The following notes were made after the transfer of the patient to Dr. Morley Fletcher's ward: Weight, 2 st. $12 \frac{1}{2} \mathrm{lb}$. Height, $3 \mathrm{ft} .2 \frac{1}{4}$ in. Systolic blood-pressure $195-170 \mathrm{~mm}$. Hg. Urine, sp. g. 1023 or less. Protein (which gave all the reactions of globulin) 0.001 per cent. Epithelial casts present. $30 \mathrm{oz}$. passed in twenty-four hours.

1 Dr. J. F. Gaskell's gelatin method was employed for the preparation of specimens for microscopical examination (9). 
Renal efficiency tests (Dr. I'revan): ' Excretion of sodium chloride indicates that tubules are probably in good working order. This was confirmed by normal excretion of potassium iodide; but there was a great rise in the water excretion, indicating that his cardio-vascular apparatus and glomeruli are disorganized. Excretion of lactose normal, and therefore glomeruli are not much damaged.' Marked cardiac hypertrophy was present at this date. The optic disks were passed as normal.

After discharge from hospital the boy remained in his usual health for six years, when his eyesight began to fail. At about the same time he began to suffer from occipital headaches, but throughout these years there was no history of oedema, frequency of micturition, haematuria, pain in the back, or other digestive disturbance than an occasional pain in the stomach half an hour after his meals.

$F . H$. Patient was seventh of nine children, having four sisters and five brothers all alive and well. His mother had four miscarriages before his birth. Mother alive and well. Father died of pneumonia.

$P . H$. Normal labour ; breast-fed to 11 months, then potatoes and gravy. Walked and talked at usual age. Measles, aged 4; broncho-pneumonia, aged 5 ; T. B. gland in neck opened, aged 8 ; bronchitis every winter. No history of chorea, rheumatism, scarlet fever, or fits.

$P . C$. Under-developed, mouth-breather, somewhat pigeon-chested, Harrison's sulcus present. Rickety bowing of the tibiae; X-ray appearances of bones of lower limbs were those of rickets. No signs of syphilis. Blood W.R. negative (as also seven years previously). No oedema. Marked cardiac hypertrophy; the radial artery was thickened; there was such marked visible and palpable pulsation in the 2nd right intercostal space that aneurysm of the aorta was suspected. X-ray examination showed a dilated aorta. B. P. $260 \mathrm{~mm}$. $\mathrm{Hg}$ systolic, $200 \mathrm{~mm}$. Hg diastolic. Optic disks : Rt. 6/18. Oedema of disk. Well-defined area of exudate to outer side of disk; star-shaped figure round the macula; patches of pigment in periphery of eye. Lt. 6/18. Haemorrhages grouped about the vessels all over the retina; black spots at macula and many at periphery; star-shaped figure round yellow spot and much exudate of like character (Mr. Foster Moore). Urine sp. g. 1012, acid, albumin 0.025 per cent.; no casts or cells in a centrifugalized deposit. Later, a fow W. B. C., granular and epithelial casts were found in the centrifugalized deposit. Average excretion of urine $45 \mathrm{oz}$. Blood urea $67 \mathrm{mg}$. per cent. (Dr. G. Graham). Potassium iodide excretion in first twelve hours 26 per cent. of dose given-normal 45 per cent. (Dr. Linder).

Three months later the patient was readmitted unconscious. He had complained of sickness and headache for the past few days. On the evening before admission he had a convulsion and became unconscious. He died soon after admission, obviously a case of cerebral haemorrhage without localizing signs.

Post-mortem, 16.8.20. Cerebral haemorrhage, left capsular, rupture into ventricles; left ventricle, hypertrophy, arterio-sclerosis ; chronic nephritis.

Heart. 12 oz., marked hypertrophy left ventricle; muscle, endocardium, and pericardium normal.

Vessels. The aorta showed only slight evidence of sclerosis. In an adult it would have passed as normal in this respect; its media was much thickened, as was that of the other vessels. In the carotids were long narrow streaks of fatty sclerosis; the vertebral and basilar arteries normal; small patches of nodular sclerosis in the middle and posterior cerebral arteries.

Kidneys. Left, 5 oz., adherent to perirenal tissues by numerous small adhesions, surface coarsely granular, mottled white and bluish red; capsule adherent and split on stripping, tearing cortex on complete removal. Organ firm on section; cortex narrowed, normal structure blurred; colour of cut surface mottled grey and purplish red with scattered pin-point haemorrhages; the pyramids somewhat dark in contrast to cortex. Pelvis increased in size; no pyelitis; increase in peri-pelvic fat. Rt., $1 \mathrm{oz}$., shrunken, globular shape. On section there 
appeared to be a congenital reduction in substance, there being only two wellformed pyramids. On the surface an indefinite smoother (? scarred) area; in other respects this organ resembled the left. Both renal arteries showed arteriosclerosis, and in the right, near its division into branches, there was a calcified oblong plaque. The ureters and urinary bladder were normal. Several enlarged easeous lymphatic glands in the mesentery. Adhesions present at base of left lung binding visceral pleura to diaphragm. Petechiae were present on the pleural surfaces of the lungs, under the peritoneum, and in the skin of the lower limbs.

Histology. Chronic nephritis showing a remarkable degree of recovery. The microscopical appearance was nnusual. The great degree of tubule regeneration dominated tho picture; the tubule epithelium stained well; sorne desquamation of cells, but the lumina, which were somewhat dilated, did not contain casts. The glomeruli showed regeneration almost uniformly. On careful examination many were found to show slight proliferation of the opithelial cells of Bowman's capsule, and there was a sparsely scattered focal lesion in the tufts resembling that found in focal embolic nephritis. There was an absence of hyaline degeneration and fibrosis of the tufts. The amount of interstitial change was relatively small; slight round-cell infiltration around some of the glomeruli and a few polynuclear cells. The typical lesion of diffuse hyperplastic sclerosis was present, and Plate 3 shows two arterioles in active phase of this lesion. The section suggested the regenerative stage of a chronic nephritis in the tubular and glomerular hyperplasia; while the relatively small degree of arterial change suggested that this tissue also had made good recovery.

Case III. Male, aged 9, admitted to hospital under the care of Dr. Drysdale six months before death, complaining of headaches and vomiting. His first admission to hospital was six months previously, when he was brought up by his mother on account of nocturnal enuresis. There was some evidence that his illness dated from an attack of scarlet fever three years before. Definite symptoms developed a year before death, namely, headache in the early morning, disappearing after breakfast, and occasional attacks of vomiting in the morning or late afternoon. Apart from the history of scarlet fever there was no fact of importance in the past or family history. There was no history of oedema, haematuria, gastro-intestinal disturbance, fits, or defective vision in the past history.

P.C. (1st admission). Poor physique, thin, pale, rather sallow complexion, with slight puffiness under the eyes, particularly in the early morning. No sign of syphilis, blood W. R. negative. Marked cardiac hypertrophy; pulse small and wiry, no appreciable thickening of the radial artery. B. P., systolic $190 \mathrm{~mm}$. $\mathrm{Hg}$, diastolic $150 \mathrm{~mm}$. Hg. Optic disks normal. Urine pale with slight flocculent deposit and slightly turbid, sp. g. 1018-1015, acid. Albumin 0.05-0.2 per cent. (Aufrecht). Centrifugalized deposit contained many hyaline casts, few granular and epithelial casts and W. B. C., no R. B. C. Average output 35 oz. MacLean's urea concentration test in first hour 1.85 per cent. urea, in the succeeding hours 1.3 per cent. Diastase (Dr. Mackenzie Wallis) 10 units. During the month he was in hospital his condition seemed to improve; he had no headache or vomiting, no nocturnal enuresis. His temperature was normal throughout; pulse-rate, 100 on admission, dropped to 70 with rest, and rose later to 90 when he got up. He kept well for six months and then began to suffer frum headaches. Four days after their onset he began to vomit, and on the following day he had a fit, became unconscious, and was admitted to hospital (2nd admission). With treatment by Iumbar puncture, venesection, and alkalinization the boy recovered from this attack of uraemia ; the condition gradually recurred and he died six weeks after admission of uraemia. During this period of treatment the following observations were made: B. P. 215/160. C. S. F. urea $60 \mathrm{mg}$. per cent. (Dr. Canti). Urine pale, turbid, sp. g. 1005. Trace of 
albumin. Centrifugalized deposit contained a few hyaline casts and occasional W. B. C. Later albumin 0.15 per cent. (Aufrecht), sp. g. 1012-1010. Many subsequent specimens of urine were examined without finding any casts or W. B. C. Optic disks showed patehes of exudate in both retinae. Diastase in urine 5 units. Urine culture and blood culture negative. Blood count: R. B. C. 2,960,000. Hb. 48 per cent. C. I. 0.8 . W. B. C. 6,400 .

Post-mortem, 20.10.20. Uraemia. Chronic nephritis. Pale, wasted, undersized body showing petechial haemorrbages in the skin of the trunk and limbs, particularly grouped about the umbilicus. Examination of the head and neck not allowed.

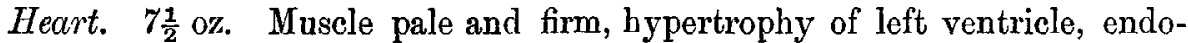
cardium and pericardium normal. Vessels very free from disease. The aorta was almost free from any arterio-sclerotic change. It showed medial hypertrophy, as did the other arteries. In the left coronary artery there was a single plaque of sclerosis. The renal arteries were normal in structure, but the left was double and the right bifurcated at a distance from the kidney.

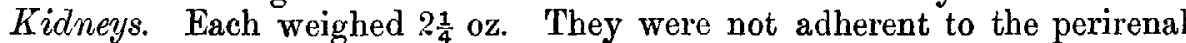
tissues and the capsule was little thickened ; it stripped readily, leaving a shiny granular surface brownish red in colour. The organ was unduly resistant on section; the pelvis somewhat increased in size, not inflamed. Cortex diminished in thickness, lack of distinction in colour between cortex and medulla, the cortex had a confused appearance with loss of distinction in the normal details of structure; cut surface mottled brownish colour with paler areas, and showing minute points of fatty or fibrous tissue. Cut vessels not unduly prominent; the ureters were hypertrophied. No hypertrophy of the bladder; a few petechial haemorrhages under its mucous membrane. Marked suprarenal hypertrophy with adenomatous overgrowth of the cortex and increase in the medulla.

Histology. Characteristic chänges of chronic nephritis of an advanced type. Parenehymatous and interstitial changes were equally prominent. There was uniform affection of the glomeruli of varying degree; the characteristic change was a proliferation of the epithelial layer of Bowman's capsule with heaping up of the cells and adhesion of the parietal and visceral layers; hyaline swelling of some of the capillary loops of the tuft, with fatty degeneration of some. A few had gone on to more complete hyaline degeneration and fibrosis. The majority showed some degree of hyperplasia ; there was little pericapsular fibrosis. Tubule changes were marked. The ordinary degenerative changes were present, with atrophy and dilatation of the convoluted tubules, fatty degeneration of the secreting cells in some areas; tubule regeneration was very considerable. The interstitial tissue was increased, there was a patehy small-cell infiltration, and the vascular changes were marked (diffuse hyperplastic sclerosis). No amyloid changes were present. Vide Plate 3.

Case IV. Female, aged 14, admitted to hospital under the care of Mr. Foster Moore on account of difficulty of vision increasing during the last month.

H.P. C. Scarlet fever ten months previously. Seemed to have made a good recovery from this; on close questioning there was evidence of loss of health since three to four months previously, in particular loss of energy and unusual fatigue. Since that date had complained at times of headache, cramps in the abdomen, and pains in the arms; during the last week severe headaches and occasional vomiting. No history of oedema, haematuria, dyspnoea, or fits.

$P$. C. Well developed, rather wasted, pale, dry skin and general diffuse pigmentation; uraemic odour in breath. Cardiac hypertrophy, present but not pronounced ; clinical evidence of slight aortic regurgitation and possibly mitral regurgitation. Radial artery not thickened. B. P. 165/123. Optic disks: Marked retinitis and some haemorrhages in left eye; two small patches of degeneration in right. Both disks swollen; haemorrhages in right disk and one 
or two small haemorrhages peripherally; exudate along vessels, and star figure at left macula. Urine pale, smoky, sp. g. 1008. Albumin plus. Centrifugalized deposit contained R. B. C. and R. B. C. casts. Blood urea $400 \mathrm{mgm}$. per cent. Blood culture negative. Blood count: R. B. C. 2,350,000. Hb. 40 per cent. C. I. 0.9 . W. B. C. 3,800 .

Ulcerative stomatitis developed rapidly; vomiting increased; petechial haemorrhages appeared in the skin and there was bleeding from the uterus. Pericarditis developed a few days before death. The patient died of uraemia.

Post-mortem. Height of child, $4 \mathrm{ft} .2$ in. Well-developed body, no skeletal deformity ; thin. No axillary or pubic hair.

Heart $8 \frac{3}{4}$ oz. Recent general pericarditis with serous effusion. Some hypertrophy of left ventricle, thickening of aortic cusps, and slight thickening of mitral cusps. No recent endocarditis. Vessels practically free from arteriosclerosis, in particular the arteries at the base of the brain, middle, anterior and posterior cerebral arteries, carotids, iliacs, coeliac axis, splenic and superior mesenteric arteries normal. Aorta throughout normal except for a few fatty streaks in the ascending aorta. Kidneys: extreme degree of chronic nepbritis. Right $\frac{3}{4}$ oz., greatly sbrunken. Left $2 \frac{1}{2}$ oz. Both adherent to perirenal tissues. Capsule stripped easily, leaving a smooth coarsely granular surface, knobbly and irregular, with bossing and in general a somewhat globular form. Colour pale, the depressions between the granules darker in colour. Cut with resistance; cut surface all trace of normal structure gone. Pelvis much increased, and in some parts extended nearly to the surface. Cortex existed as a whitish streak between atrophied pyramids, and contained retention cysts the size of a small pea filled with a yellow gelatinous fluid. Thickening of renal arteries, but no pouting of vessels on cut surface of kidney. Suprarenals hypertrophied.

Histology. An active state of chronic nephritis. The microscopical appearances need not be given in detail as they closely resembled those seen in Case III, except that they were moro active. The active proliferation of the epithelial cells of Bowman's capsule was pronounced, tubular hypertrophy was less prominent, and the degenerative changes in the tubules more marked. There was an increase in the interstitial tissue and intense small-cell infiltration. The active state of these and the renal lesion was probably associated with the presence of a terminal secondary infection. The picture was entirely comparable to that seen in adult cases dying of chronic nephritis. The vascular lesion was well marked, and was that of diffuse hyperplastic selerosis. See Plate 5.

The presence or absence of a lesion of the intimate vasculature of the organs examined microscopically is given in the following table:

Organ.

Kidney

Spleen

Suprarenal

Pancreas

Small intestine

Large intestine

Stomach

Liver

Lungs

Thyroid

Brain

Heart
Case I.

Marked

Marked

Present

Present

Present

Present

Slight

Slight

Absent

Absent

Slight, atypical

Slight, atypical
Case II.

Present

Not examined

Present

Not examined

Present

Present

Present

Not examined

Not examined

Absent

Absent

Absent
Case III.

Marked
Marked
Present
Present
Not examined
Not examined
Not examined
Slight
Slight
Not examined
Not examined
Absent

Case IV.

Marked
Marked
Present
Present
Absent
Absent
Absent
Absent
Absent
Not examined
Not examined
Absent

The radial artery was examined in Case I, and apart from medial hypertrophy was found to be normal. 


\section{Identity of the Vascular Lesion found in these Children with Diffuse Hyperplastic Sclerosis in Adults.}

In the first place the actual lesion as it affects the terminal arterioles and their parent vessels (best seen in the kidneys) is the same as diffuse hyperplastic sclerosis in adults (10). There is swelling and fatty degeneration of the intima of the arterioles, leading to a greater or less degree of obliteration of the arteriole lumen; frequently the lumen appears to be completely obliterated. At the same time there is proliferation of the intima without fatty degeneration in the parent vessels of the arterioles. Secondly, the vascular lesion affects the intimate vasculature of the organs rather than the larger arteries. This distribution of the lesion within the vascular tree is well illustrated by the present four cases, in three of which the larger arteries are inappreciably diseased, while in the fourth (Case I) it is only the aorta and vessels at the base of the brain that showed much sclerosis. Thirdly, the incidence of the lesion in the various organs follows that found in adults in its main features; that is to say, the kidney and spleen are most affected, the pancreas and suprarenals are next in order, the affection of the intimate vasculature of the liver is slight and the heart escapes. It is noted that the vessels in the brain were not affected in these cases, whereas those in the stomach and intestines were. In these two respects the incidence of the lesion is different to that in adults. The finding of the lesion in the stomach and intestines is interesting because in my experience the lesion is infrequent in this situation in adults; its absence in the brain is only referred to for the sake of fairness, since in only two of the four cases was the brain examined, and in one of these the material was poor. Fourthly, and lastly, the vascular lesion was associated with left ventricular hypertrophy and a raised blood-pressure. These several points establish the identity of diffuse hyperplastic sclerosis in children and adults.

\section{Part played by the Endothelium in Intimal Proliferation.}

In material taken from adults $I$ have not been able to demonstrate active endothelial proliferation in diffuse hyperplastic sclerosis. In some specimens the shadows of endothelial cells that had undergone fatty degeneration were visible (12). In these children, however, examples have been found of the earlier active phase of this lesion (vide Plate 3). These specimens, therefore, supply further histological evidence that diffuse hyperplastic sclerosis is an active inflammatory lesion, and complete the link between arterio-sclerosis and such obvious endarteritis as is seen in tuberculosis and syphilis.

Whereas in adults the arterioles seemed to undergo a swelling of their intima with subsequent fatty degeneration leading to obliteration of the lumen, while the parent vessels showed active proliferation of the intima without fatty degeneration, these specimens taken from children seem to show that an earlier 
phase of the arteriole lesion has escaped observation in adults; that, in fact, the arteriole lesion is primarily one of active cellular proliferation similar to that which occurs in the parent vessels, and that the cells which proliferate are the endothelial cells.

\section{The Bearing of these Observations on the Aetiology of Arterio-sclerosis.}

The conclusion arrived at from the study of these cases, that arteriosclerosis in children and adults is identical, is not in itself an original observation. In his article on arterio-sclerosis in the Text-book of Diseases of Children (Garrod, Batten, and Thursfield) Dr. Poynton makes the same statement. The histological observations made in these cases, however, not only confirm the previous work of others, but go a step farther in that they demonstrate the identity of a particular type of arterial lesion, diffuse hyperplastic sclerosis, in children and adults. This identity is confirmed in detail in the nature of the lesion of the arterial wall, its distribution in the vascular tree and its incidence in the several organs, and its association with a raised blood-pressure and left ventricle hypertrophy. Arterio-sclerosis in general terms is not an uncommon lesion in children; it is known to result from acute infections and from syphilis, and to occur in association with kidney disease. By defining the particular type of arterial lesion present in a case the problem of its causation is in a degree simplified, and it is for future observation to determine whether this particular type of arterio-sclerosis occurs in syphilitic children apart from kidney disease, whether it can be caused by acute infections apart from lkidney disease, whether in fact it ever occurs in children without simultaneous disease of the kidneys.

It is possible that by the definition of diffuse hyperplastic sclerosis in children this problem of the association of arterio-sclerosis with chronic nephritis may be simplified in another direction. Hitherto it has been difficult to account for the presence in some cases and the absence in others of a raised bloodpressure and cardiac hypertrophy. Thus Miller and Parsons (4) in describing the cases of their first group with renal disease write: 'Cases in this group have many similarities and only two points of difference; these latter consist of the presence or absence of cardio-vascular changes, and the age at which the symptoms were first noticed. These clinical differences are of considerable interest, which is enhanced by the fact that they do not appear to correspond to any pathological differences.' (Italics mine.) This may be true so long as microscopical study of these cases is limited to the kidneys, but if the pathology of the disease in children follows the line that it appears to in adults, it may be found that in those patients without cardiac hypertrophy and raised bloodpressure the vascular lesion (in so far as it affects the intimate vasculature of organs) is practically limited to the kidneys, whereas in those cases with a raised blood-pressure and cardiac hypertrophy the vascular lesion is widely distributed, as it was found to be in the present series. 
It cannot be said that the present observations throw any new light on the nature of the association of chronic nephritis and arterio-sclerosis. The endothelial proliferation seen in arteriole walls, of which these are believed to be the first examples seen in diffuse hyperplastic sclerosis, is further histological evidence of the active inflammatory nature of this vascular lesion. Further, the active inflammatory change observed in the kidneys of all four cases, particularly the proliferation of the epithelial cells of Bowman's capsule, is evidence of a primary affection of the renal parenchyma, and it is suggested that proliferation of such specialized cells would not result from the starvation of a glomerulus of its blood supply; it indicates, in fact, that the renal lesion is primary and not the secondary result of vascular disease. It is equally difficult to interpret the vascular lesion as a direct result of renal disease in this limited sense that the vascular lesion is one of arterial involution. For in the first place, as previously shown (11), fatty degeneration is not a part of the histological picture of involution; and in the second place such a point of view will not explain the wide distribution of the vascular lesion in these four cases. At present, the simplest conception is to regard the vascular and renal lesions as simultaneous results of the action of a single pathogenic agent.

There remains, however, another interpretation, namely, the possibility that renal disease indirectly causes arterial disease, perhaps through the toxaemia that inefficient renal function produces. Such an interpretation is suggested by the unique case reported by Hale-White (13), in which, in a boy aged 6 months, the most extensive and unusual type of arterio-sclerosis was associated with bilateral hydronephrosis and extreme cirrhosis of the kidneys due to phimosis. The author was of the opinion that syphilis was the main aetiological factor in this case, and that the kidney disease was a contributory cause.

As regards these two aetiological factors in the present cases it is unlikely that syphilis played a part. Except in Case II, whose birth was preceded by four miscarriages, there was rothing in the past or family history of the patients to suggest syphilis; there was no clinical sign of syphilis and the blood Wassermann reaction, which was done in Cases I, II, and III, was negative. It is generally agreed that cases of chronic nephritis in children of the particular type to which the present series belong are not syphilitic. The congenital defect of the right kidney in Case II is, on the other hand, some indication of a primary renal affection. It is a commonplace in pathology that congenitally deformed organs are particularly prone to disease, and Dr. Spilsbury, whose help in disentangling the histology of these specimens I gratefully acknowledge, has told me that in his opinion this general statement seems to be especially true of the kidneys. It is possible that congenital polycystic kidneys, which are so often associated with arterial disease, are an example of a primary and congenital renal affection that is responsible for arterial disease. In Case III there was a congenital abnormality of both renal arteries, a fact which may have a similar significance. While these two cases provide anatomical evidence of a congenital defect the clinical history of Case I indicates a very early onset: 
of the affection; the onset of the complaint, if not congenital, must have been acquired in utero or in early infancy.

Scarlet fever remains for consideration as a possible aetiological factor. Case I suffered from scarlet fever, but only after the disease of the kidneys was fully developed, and it did not influence its course. It is possible that scarlet fever initiated the morbid series in Case III ; the patient's mother was not a good witness. In Case IV, which differed from the others in its later age of onset and in its more rapid course, it was reasonable to assume that scarlet fever was the responsible cause.

\section{Conclusions.}

1. Diffuse hyperplastic sclerosis is identical in children and adults.

2. Its association with chronic nephritis in children is more significant than in adults, because many of the causes of arterio-sclerosis are excluded in children by reason of their age.

\section{REFERENCES.}

1. Evans, Geoffrey, Quart. Journ. of Med., Oxford, 1921, xiv. 240.

2. Fletcher, H. Morley, Proc. Roy. Soc., 1920, xiii. 118.

3. Rach, Egon, Jahrb. der Kinderheilk., 1907, lxv. 221.

4. Miller, R., and Parsons, L., Brit. Journ. Child. Dis., 1912, ix. 289.

5. Glaser, F., Jahrb. der Kinderheilk., 1918, xxxvii. 95.

6. Hill, L. W., Amer. Joum. Dis. of Child., 1919, xvii. 270.

7. Paterson, D. H., Proc. Roy. Soc., 1920, xiii. 107.

8. Barber, Hugh, Quart. Journ. of Med., 1921, xiv. 205.

9. Gaskell, J. F., Joum. Path. Bact., 1912, xvi. 287.

10. Evans, Geoffrey, ibid., 219.

11. Evans, Geoffrey, ibid., 230.

12. Evans, Geoffrey, ibid., Plate 4, Fig. 7.

13. Bryant and Hale-White, Sir Wm., Guy's Hospital Reports, lv, 17.

\section{DESCRIPTION OF PLA'TES.}

Plate 3. Case II. Magnification $\times 480$. The two arterioles shown in cross-section were found in the kidney of Case II. The lumen of the lower arteriole appears to be completely occluded; this is the common appearance in adult diffuse hyperplastic sclerosis. The upper arteriole shows an earlier stage of the same process; multiplication of the endothelial cells has occurred; those situated peripherally are much swollen and have undergone fatty degeneration, while those bordering the lumen have large clearly staining nuclei and seem to be actively proliferating. There is no change in the media, except perhaps some hypertrophy. The section is stained with haemalum and Sudan 3. The fat-staining of those cells which appear filled with fine black dots in this reproduction was intonse; the fat-staining was limited to these cells. 
Case III. Magnification $\times 480$. An arteriole showing endothelial proliferation in a stage intermediate to that seen in the two arterioles in Case II.

Plate 4. Case III. Magnification $\times 175$. Section of kidney from Case III showing the changes characteristic of chronic nephritis, except that this particular field does not happen to show any small-cell infiltration. In the left top corner is a glomerulus in which there is confusion of normal structure and decrease in the number of nuclei present due to hyaline degeneration of the capillaries of the tuft; there is heaping up of proliferated epithelial cells of Bowman's capsule into crescent-shaped masses. On the right is a distended empty venule, and adjoining it a degenerated glomerulus sliced across the top. Next to this is one of the vasa recta showing intimal proliferation, below which is an arteriole (vas afferens) with hypertrophied media. The larger artery to the right, cut rather obliquely, shows marked intimal proliferation without fatty degeneration, and in the top right-hand corner is an arteriole characteristic of diffuse hyperplastic sclerosis, its lumen being blocked with a swollen (once proliferated) intima which has undergone fatty degeneration. Half-way down on the left is a patch of oedematous fibrous connective tissue which fills a space left by the atrophy of tubules or glomeruli; next to this are numerous dilated tubules, whose lumen is filled with desquamated cells, hyaline, and granular débris which occasionally takes up a little Sudan 3 stain. The large tubules are examples of tubule hyperplasia; finally, a single partly hyaline and partly fibrotic glomerulus is seen to the right of the centre.

Prate 5. Case 1V. Magnification $\times 275$. These figures show three characteristic forms of glomerular lesion. In this case the interstitial reaction was very marked, and there was a great deal of small-cell infiltration. The glomerulus on the left above shows the endoglomerulitis characteristic of chronic nephritis; there is hyaline degeneration of the tuft with early fatty degeneration (seen as fine black spots) and proliferation of the epithelial cells of Bowman's capsule. In addition, both in this glomerulus and that to the right, there is pericapsular fibrosis. Hyaline degeneration of the tuft has reached an advanced stage in the second glomerulus. In the third glomerulus the tuft is somewhat shrunken, but the main pathological change is a pericapsular fibrosis. 


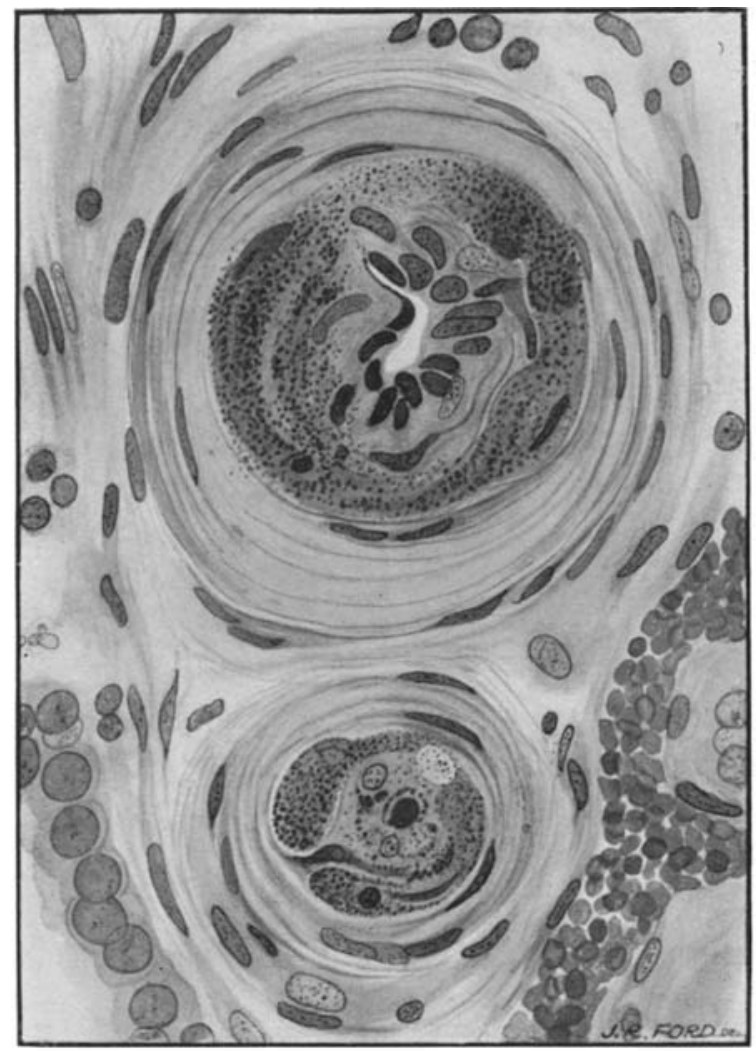

Case II

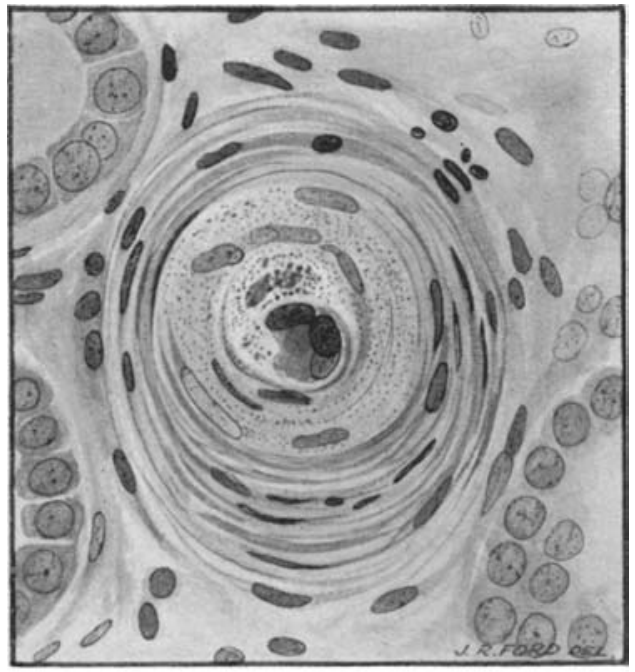

Case III $\times 480$ 
Tol. 11; 17. A

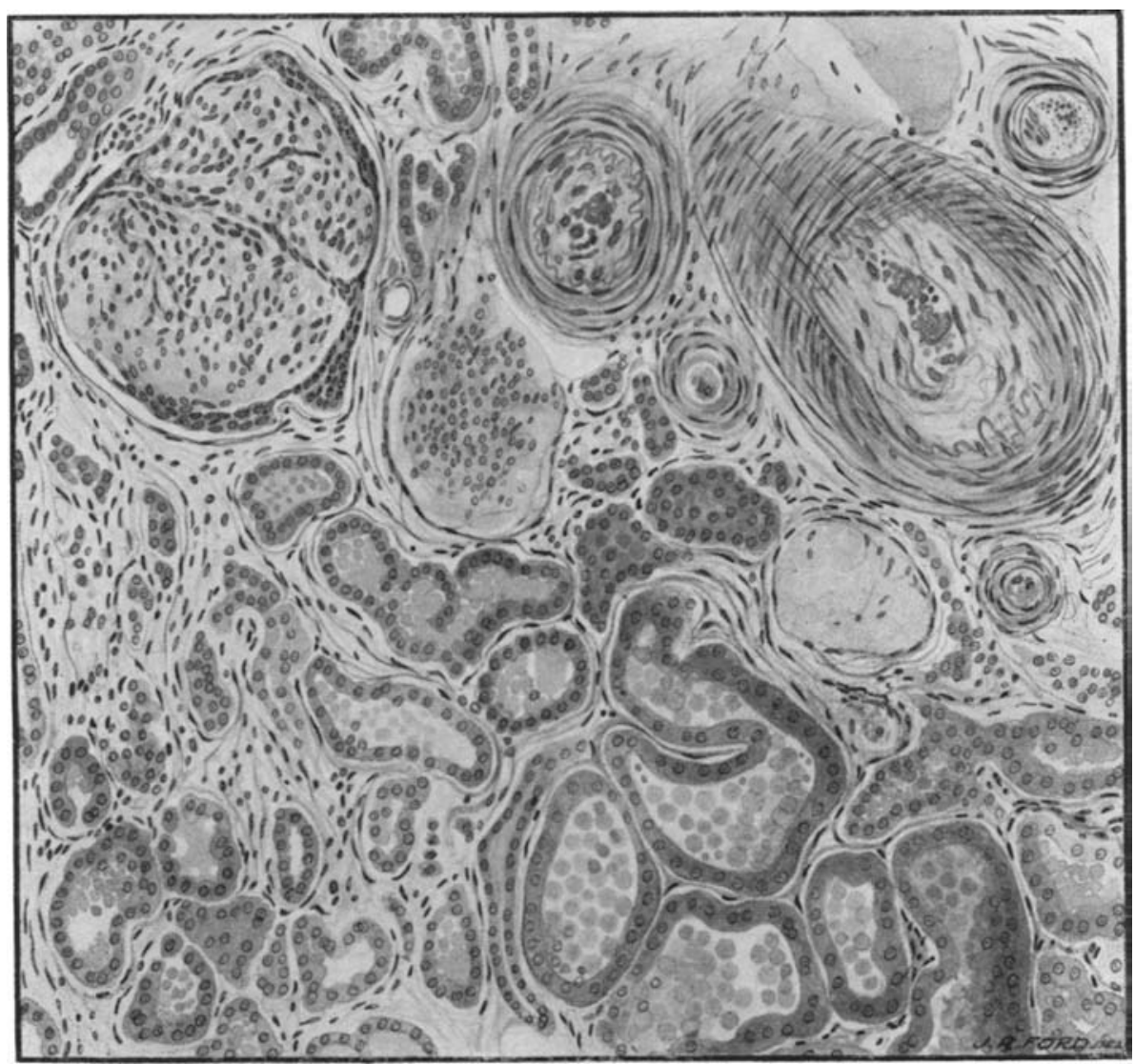



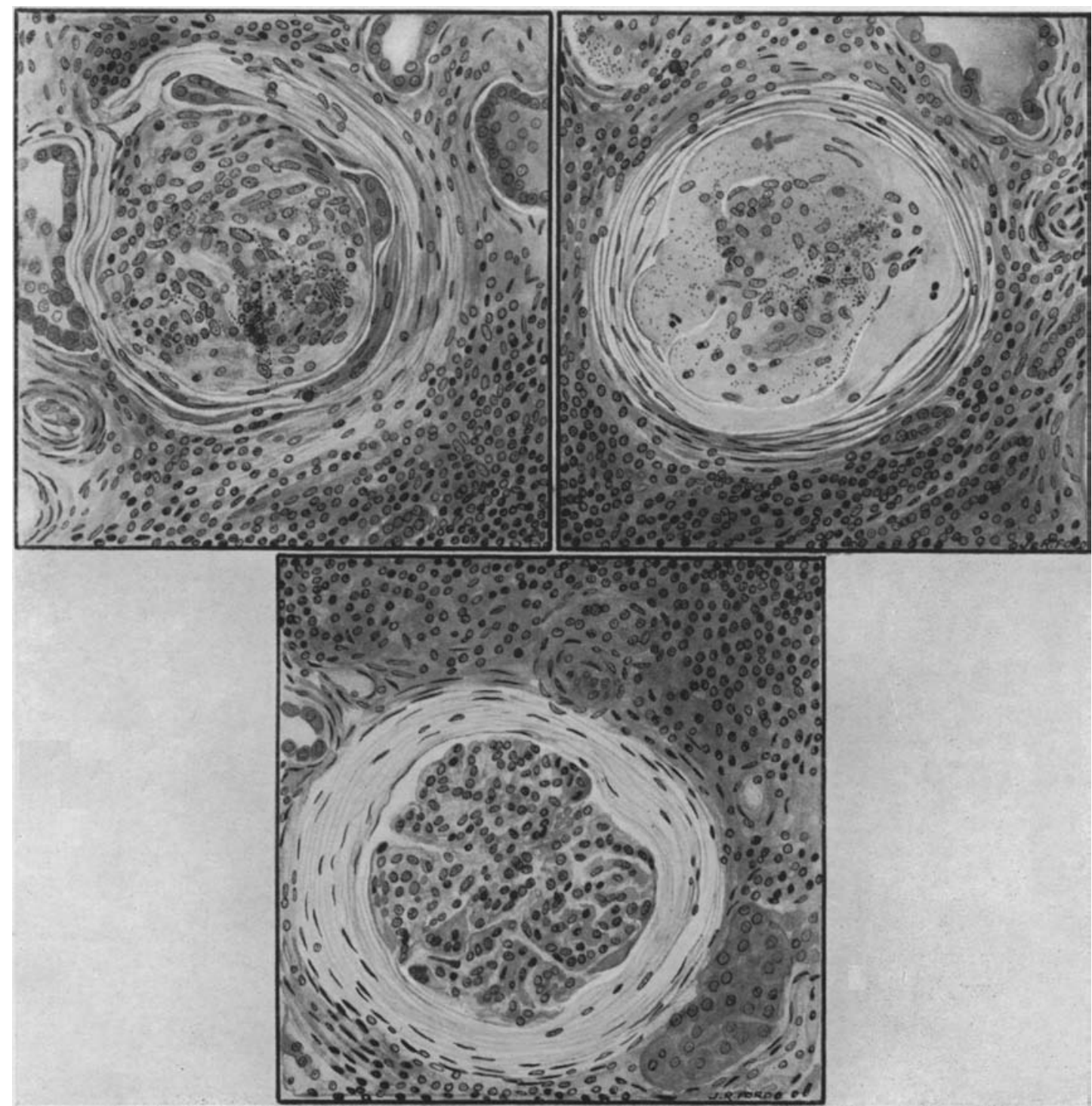

Case IV 